\section{Bruno Hochhegger}

Received: 4 December 2008

Accepted: 21 December 2008

Published online: 24 February 2009

(C) European Society of Radiology 2009

The authors' reply to this Letter to the Editor is available at doi:10.1007/s00330-009-

1324-7.

B. Hochhegger

Post Graduation Program in Pulmonary

Sciences of Federal University

of Rio Grande do Sul,

Pavilhão Pereira Filho Hospital,

Rua Anes Dias 212,

Porto Alegre, Brazil

B. Hochhegger $(\bowtie)$

Post Graduation Program

in Radiological Sciences of Federal

University of Rio de Janeiro,

Rua João Alfredo 558/301,

90050230 Porto Alegre, Brazil

e-mail: brunohochhegger@gmail.com

Tel.: +55-51-93563666

\title{
CT of pulmonary emphysema: current status, challenges, and future directions
}

Dear Sir,

I would like to congratulate Dr. Litmanovich and colleagues on their beautiful and useful review [1], but I would like to highlight the following two statements: 1. "The introduction of multidetector CT units now allows acquisition of such high-resolution CT in a volumetric manner over the entire lung, and this approach has been shown to be suitable for the assessment of emphysema [22]." 2. "From these observations, Madani et al. concluded that the relative lung areas with attenuation coefficients lower than -960 or $-970 \mathrm{HU}$ and first percentile were valid indexes to quantify pulmonary emphysema on multidetector row CT scans."

For these statements, the authors refer to a paper by Dr. Madani [2]; however, the problem is that despite the use of volume data, axial reconstructions were performed for assessment of emphysema and histo- pathologic correlation and an extrapolation of these findings for volumetric data is not reliable. To the best of my knowledge, no paper has reported the correlation of volumetric data with histological specimens, presumably because of the associated technical difficulties. I hope this small comment encourages investigators to reach a definitive solution to this issue.

\section{References}

1. Litmanovich D, Boiselle PM, Bankier AA (2008) CT of pulmonary emphysema: current status, challenges, and future directions. Eur Radiol. doi:10.1007/s00330-008-1186-4

2. Madani A, Zanen J, de Maertelaer V, Gevenois PA (2006) Pulmonary emphysema: objective quantification at multi-detector row CT-comparison with macroscopic and microscopic morphometry. Radiology 238:10361043 